V. Asnaghi · R. Lattanzio - G. Mazzolari •

M. R. Pastore - A. Ramoni - A. Maestroni •

D. Ruggieri $\cdot$ L. Luzi $\cdot$ R. Brancato $\cdot$ G. Zerbini

\title{
Increased clonogenic potential of circulating endothelial progenitor cells in patients with type 1 diabetes and proliferative retinopathy
}

Received: 27 July 2005 / Accepted: 3 January 2006 / Published online: 7 March 2006

(C) Springer-Verlag 2006

To the Editor:

The identification of endothelial progenitor cells (EPCs) along with the description of their essential role in postnatal neovascularisation has been a major achievement for stem cell biology [1].

In particular the finding that the clonogenic potential of EPCs is reduced in patients with high cardiovascular risk [2] represents the first step towards the recognition of the therapeutic effect of EPC transplantation in cardiac and limbic ischaemia $[3,4]$.

However, two harmful side effects are expected to be associated with EPC transplantation as a consequence of their physiological function: malignant tumour neovascularisation and the induction of proliferative diabetic retinopathy [1]. The contribution of EPCs to tumour neovascularisation has been clearly demonstrated in animal models and confirmed, although to a lesser extent, also in humans [5].

Concerning diabetic retinopathy, recent reports have demonstrated that EPCs play a major role in the retinal neovascularisation of a mouse model of proliferative retinopathy [6], and that the concentration of stromalcell-derived factor 1, the most important chemokine mobilising EPCs, increases with the severity of diabetic retinopathy in vitreous samples of patients affected by type 2 diabetes [7]. These studies are in some way in contrast to two independent reports performed in non-complicated

V. Asnaghi · G. Mazzolari · M. R. Pastore - A. Maestroni ·

D. Ruggieri · L. Luzi · G. Zerbini $(\bowtie)$

Renal Pathophysiology of Diabetes Unit,

Division of Nutrition-Metabolism,

San Raffaele Scientific Institute,

Via Olgettina 60,

20132 Milan, Italy

e-mail: g.zerbini@hsr.it

R. Lattanzio · A. Ramoni - R. Brancato

Department of Ophthalmology and Visual Sciences,

San Raffaele Scientific Institute,

Via Olgettina 60,

20132 Milan, Italy patients showing that type 1 diabetes per se is associated with a reduced number and function of EPCs [8], and that EPCs in type 2 diabetes are impaired in adhesion, proliferation and tubulisation [9].

Finally, a recent study has demonstrated an increased number of CD34+ mononuclear cells in patients affected by type 2 diabetes with both non-proliferative and proliferative retinopathy [10]. Although of interest, these results cannot be easily compared with the ones described above as EPCs represent only one of the different classes of circulating cells staining positively for CD34+ [1]

Taken together, and from a largely speculative point of view, these apparently discrepant results can be explained by a unifying hypothesis. Taking into account the fact that EPCs have a physiological role in the rescue and maintenance of the existing retinal capillary bed [11], it is possible to hypothesise that the reduced number and clonogenic potential of EPCs found in non-complicated diabetic patients $[8,9]$ might predispose these patients to the later development of diabetic retinopathy. Once the damage is widespread and specific chemokines are produced by the suffering retina, the bone marrow would respond by increasing the production of EPCs, which at this stage, possibly because of the high ambient glucose and/or the badly damaged retina, would give rise to an incompetent neoangiogenesis.

To test this hypothesis and verify the possible association between the clonogenic potential of circulating EPCs and proliferative diabetic retinopathy, we isolated EPCs from whole blood obtained from 11 patients with type 1 diabetes and untreated proliferative retinopathy, from 12 patients without retinopathy despite similar age, gender distribution and duration of type 1 diabetes, and from 11 age- and sex-matched non-diabetic controls. Patients affected by type 1 diabetes took no medication other than insulin. Clinical characteristics of subjects included in the study are described in Table 1.

Patients were classified with respect to the status of diabetic retinopathy by means of stereoscopic fundus examination and fluorescent angiography. Patients considered for this study either had no signs of diabetic 
Table 1 Clinical features of individuals involved in the study (means \pm SEM)

\begin{tabular}{|c|c|c|c|}
\hline & \multicolumn{2}{|c|}{ Patients with type 1 diabetes } & \multirow{2}{*}{$\begin{array}{l}\text { Control } \\
\text { subjects }\end{array}$} \\
\hline & $\begin{array}{l}\text { With } \\
\text { retinopathy }\end{array}$ & $\begin{array}{l}\text { Without } \\
\text { retinopathy }\end{array}$ & \\
\hline Age (years) & $29.7 \pm 1.9$ & $31.2 \pm 1.7$ & $31.3 \pm 2.7$ \\
\hline $\begin{array}{l}\text { Duration of diabetes } \\
\text { (years) }\end{array}$ & $21.3 \pm 0.9$ & $21.9 \pm 2.2$ & - \\
\hline Sex (male/female) & $5 / 6$ & $7 / 5$ & $6 / 5$ \\
\hline $\mathrm{HbA}_{1 \mathrm{c}}(\%)$ & $10.6 \pm 0.3$ & $8.6 \pm 0.6^{\mathrm{a}}$ & - \\
\hline Glycaemia (mmol/1) & $9.5 \pm 0.7$ & $8.8 \pm 0.7$ & $5.2 \pm 0.1$ \\
\hline
\end{tabular}

${ }^{\mathrm{a}} p=0.01$ vs patients with type 1 diabetes and retinopathy

retinopathy (Early Treatment Diabetic Retinopathy Study [ETDRS] grading scale $<10$ ) or were affected by proliferative retinopathy (ETDRS grading scale >61) [12]. Investigators who measured the number of colony-forming units of EPCs were blinded for the retinal status of patients enrolled in the study.

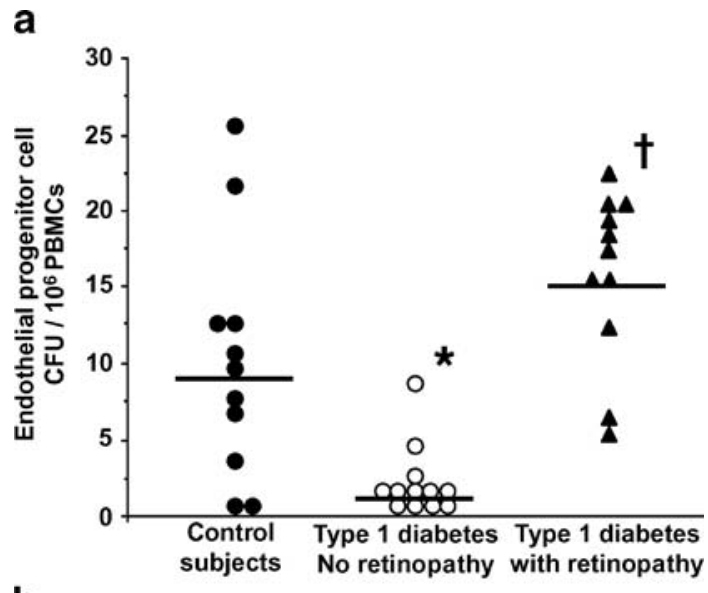

b

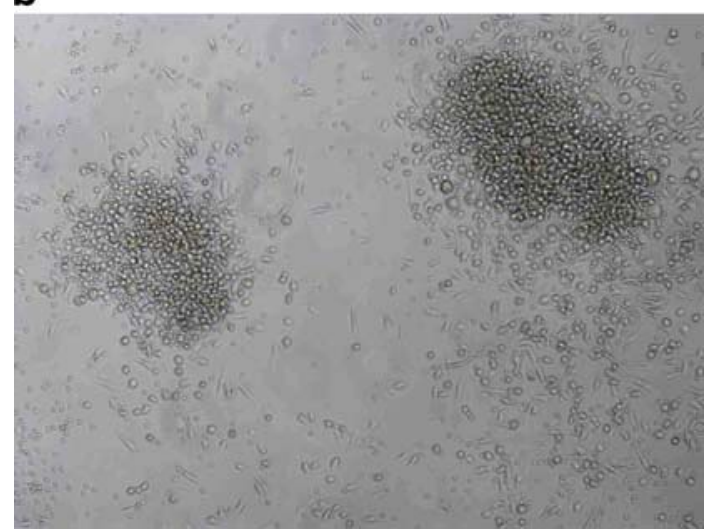

Fig. 1 a Number of EPC colony-forming units (CFUs) per $1 \times 10^{6}$ PBMCs in non-diabetic control subjects and in patients affected by type 1 diabetes with and without proliferative retinopathy. ${ }^{*} p=0.009$ vs control subjects; $\dagger p=0.0001$ vs patients affected by type 1 diabetes without retinopathy. b Representative phase-contrast micrograph of two EPC colony-forming units, characterised by thin flat cells outgrowing from a central cluster of rounded cells
The number of colony-forming units of EPCs was measured in peripheral blood samples according to the method described by Hill et al. [2], with minor modifications. Briefly, peripheral blood monocyte cells (PBMCs) were isolated and seeded into Petri dishes previously coated with endothelial cell attachment factor (Sigma, St Louis, MO, USA). Cells were cultured in M199 medium supplemented with $20 \%$ fetal bovine serum. Forty-eight hours after seeding, supernatant was removed, PBMCs were detached by trypsinisation and resuspended. After spinning $(2,000 \mathrm{~g}$ for $10 \mathrm{~min})$, cells were spun and reseeded $\left(1 \times 10^{6}\right.$ per well) into 24 -well plates. Seven days after seeding, the experiment was stopped and colonyforming units of EPCs were counted in a minimum of ten wells for each patient.

Confirmation of endothelial-cell lineage was performed in random samples by indirect immunostaining using specific antibodies directed against CD31 and CD133 [13].

Data are shown as arithmetical means with SEM. Comparisons between groups were by ANOVA and multiple comparisons by the Tukey-Kramer test (JMP software for the Apple Macintosh; SAS Institute, NC,
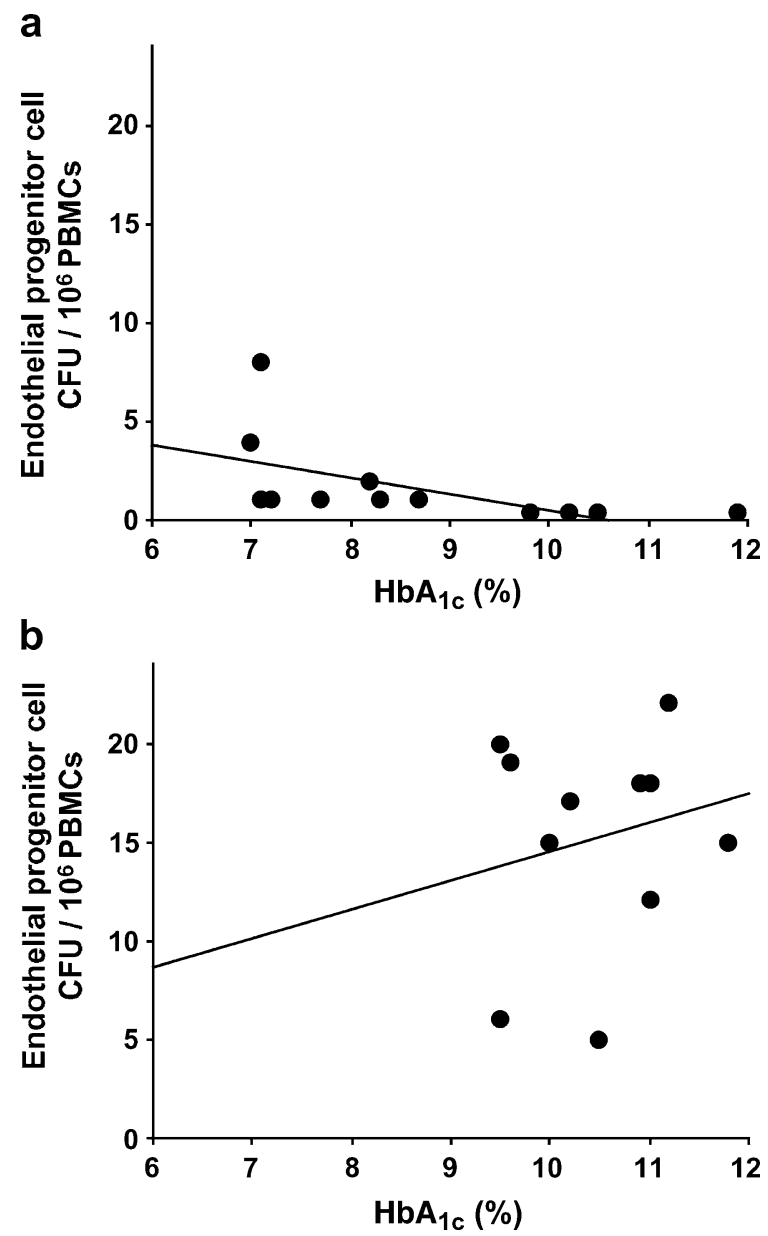

Fig. 2 Correlation between $\mathrm{HbA}_{1 \mathrm{c}}$ and number of endothelial progenitor cell colony-forming units (CFUs) per $1 \times 10^{6}$ PBMCs in patients without retinopathy $\left(\mathbf{a} ; r^{2}=0.34, p<0.05\right)$ and with retinopathy $\left(\mathbf{b} ; r^{2}=0.05, p=\mathrm{NS}\right)$ 
USA). Correlation of EPC colony-forming units and $\mathrm{HbA}_{1 \mathrm{c}}$ was performed by linear regression analysis. The null hypothesis was rejected at the 5\% level (two-tailed).

As shown in Fig. 1, we found that the number of EPC colony-forming units per $1 \times 10^{6}$ PBMCs was increased in patients with proliferative retinopathy $(15.4 \pm 1.7$ colonies \pm SEM) when compared with patients without retinopathy $(1.6 \pm 0.7, p=0.0001)$. Non-diabetic controls showed an intermediate number of EPC counts $(9.5 \pm 2.4)$ that were nonetheless significantly increased with respect to patients without retinopathy. As shown in Fig. 2a, in patients without retinopathy there was an inverse correlation between the number of colony-forming units and $\mathrm{HbA}_{1 \mathrm{c}}$ $(p<0.05)$, confirming previous results $[7,8]$. No correlation between these two parameters was found in patients with proliferative retinopathy (Fig. 2b). Although, as shown in Table $1, \mathrm{HbA}_{1 \mathrm{c}}$ was significantly increased in diabetic patients with proliferative retinopathy $(p=0.01)$, it seems rather unlikely that this phenomenon might be responsible for differences in clonogenic potential between patients with and without retinopathy because, as already described above, the clonogenic potential of EPCs is inversely proportional to $\mathrm{HbA}_{1 \mathrm{c}}$ levels $[7,8]$.

Our results are therefore in line with previous reports since they show that non-complicated diabetes is associated with a reduced number of EPC colony-forming units (non-diabetic controls vs diabetic patients without retinopathy: $p=0.009$ ) and that this phenomenon is in some way dependent on blood glucose control. This association is totally lost in patients with proliferative retinopathy, possibly suggesting a role of the injured retina in the mobilisation of EPCs from the bone marrow. This phenomenon could also account for the lack of difference of EPC colony-forming units between patients with proliferative retinopathy and non-diabetic controls.

In conclusion, we provide evidence that proliferative diabetic retinopathy is characterised by an increased clonogenic potential of EPCs and we believe that retinal status should be carefully monitored when EPCs are transplanted into patients affected by diabetes. In addition, the above-described hypothesis that EPCs may be involved in the pathogenesis of different stages of diabetic retinopathy cannot be ruled out by the present results.

Finally, and essentially from a speculative point of view, if our findings are confirmed by a parallel increase in the number of EPCs embedded in the vitreous and retina of patients affected by proliferative diabetic retinopathy, the use of EPCs as delivery agents for conventional or gene therapy of proliferative diabetic retinopathy can be envisaged.

\section{References}

1. Asahara T, Kawamoto A (2004) Endothelial progenitor cells for postnatal vasculogenesis. Am J Physiol Cell Physiol 287: C572-C579

2. Hill JM, Zalos G, Halcox JP et al (2003) Circulating endothelial progenitor cells, vascular function, and cardiovascular risk. N Engl J Med 348:593-600

3. Assmus B, Schachinger V, Teupe C et al (2002) Transplantation of progenitor cells and regeneration enhancement in acute myocardial infarction (TOPCARE-AMI). Circulation 106:3009-3017

4. Yamamoto K, Kondo T, Suzuki S et al (2004) Molecular evaluation of endothelial progenitor cells in patients with ischemic limbs: therapeutic effect by stem cell transplantation. Arterioscler Thromb Vasc Biol 24:192-196

5. Peters BA, Diaz LA, Polyak K et al (2005) Contribution of bone marrow-derived endothelial cells to human tumor vasculature. Nat Med 11:261-262

6. Grant MB, May WS, Caballero S et al (2002) Adult hematopoietic stem cells provide functional hemangioblast activity during retinal neovascularization. Nat Med 8:607-612

7. Butler JM, Guthrie SM, Koc M et al (2005) SDF-1 is both necessary and sufficient to promote proliferative retinopathy. $\mathrm{J}$ Clin Invest 115:86-93

8. Loomans CJ, de Koning EJ, Staal FJ et al (2004) Endothelial progenitor cell dysfunction: a novel concept in the pathogenesis of vascular complications of type 1 diabetes. Diabetes 53: 195-199

9. Tepper OM, Galiano RD, Capla JM et al (2002) Human endothelial progenitor cells from type II diabetics exhibit impaired proliferation, adhesion, and incorporation into vascular structures. Circulation 106:2781-2786

10. Lee IG, Chae SL, Kim JC (2005) Involvement of circulating endothelial progenitor cells and vasculogenic factors in the pathogenesis of diabetic retinopathy. Eye 20:1-7

11. Otani A, Kinder K, Ewalt K, Otero FJ, Schimmel P, Friedlander M (2002) Bone marrow-derived stem cells target retinal astrocytes and can promote or inhibit retinal angiogenesis. Nat Med 8:1004-1010

12. ETDRS report number 11 (1991) Classification of diabetic retinopathy from fluorescein angiograms. Early Treatment Diabetic Retinopathy Study Research Group. Ophthalmology 98:807-822

13. Shaw JP, Basch R, Shamamian P (2004) Hematopoietic stem cells and endothelial cell precursors express Tie-2, CD31 and CD45. Blood Cells Mol Dis 32:168-175 